\title{
Polyurethane Structural Adhesives Applied in Automotive Composite Joints
}

\author{
Josue Garcia Quini ${ }^{\mathrm{a}, \mathrm{b} *}$, Gerson Marinucci ${ }^{\mathrm{b}}$ \\ ${ }^{a}$ Masterpol Adhesives Technology, Rua Luiz Vaz de Camoes, 98, CEP 07210-007, São Paulo, SP, Brazil \\ ${ }^{\mathrm{b}}$ Nuclear and Energetic Research Institute - IPEN/CNEN-SP, \\ Av. Prof. Lineu Prestes, 2242, CEP 05598-900, São Paulo, SP, Brazil
}

Received: August 14, 2011; Revised: March 15, 2012

\begin{abstract}
In recent years structural adhesives technology has demonstrated great potential for application due to its capacity to transform complex structures into solid unitary and monolithic assemblies using different materials. Thus, seams or joints integrate these structures providing, besides a reduction in weight, a considerable increase in the mechanical resistance and stiffness. The increase in the industrial use of structural adhesives is mainly due to their ability to efficiently bond different materials in an irreversible manner, even replacing systems involving mechanical joints. In the automobile industry structural adhesives have been widely used for the bonding of metal substrates, thermoplastics and composites, frequently employing these in combination, particularly glass fiber and polyester resin composites molded using RTM and SMC processes. However, the use of urethane structural adhesives in applications involving composites and thermoplastics has been the subject of few investigations. In this study the effects of temperature and time on the shear strength of RTM, SMC and ABS joints, applying temperatures of $-40,25,80,120$ and $177^{\circ} \mathrm{C}$ and times of 20 minutes and 500 hours, were determined. The objective was to evaluate the performance under extreme conditions of use in order to assess whether these joints could be used in passenger or off-road vehicles. The results showed that the urethane structural adhesive promoted the efficient bonding of these materials, considering that due to the high adhesive strength the failures occurred in the substrates without adversely affecting the bonded area. For each test condition the joint failure modes were also determined.
\end{abstract}

Keywords: adhesion, urethane adhesive, structural adhesive

\section{Introduction}

The demands of modern industries such as those of the automotive, aeronautic and shipbuilding sectors, where there is a strong commitment to increasing productivity, with requirements for high quality indices, have lead to an ever increasing use of structural adhesives on their assembly lines. The advantages offered by structural adhesives in relation to traditional mechanical joints, such as welds, rivets or screws, include the possibility to bond distinct materials with different thermal expansion coefficients, obtaining monolithic structures which are mechanically extremely resistant ${ }^{1}$. It is also possible to achieve a reduction in weight, greater stiffness and better surface finish than bonds formed by mechanical fixing ${ }^{2}$.

In recent decades, the automotive industry, in particular, has evaluated new materials aimed at attaining better vehicle performance and structural adhesives have contributed to this objective, permitting not only the bonding of traditional metal materials with polymeric materials and composites, but also the bonding between these types of materials themselves.

The bonding of parts using structural adhesives offers significant benefits in relation to traditional systems. The adhesive distributes the loads and stresses acting on the total

*e-mail: josue@masterpol.com.br bond area instead of concentrating them, allowing not only a uniform distribution of static and dynamic loads but also reducing the production and maintenance costs in relation to mechanically fixed systems. Furthermore, it ensures better electrical insulation, a reduction in corrosion and also a reduction in the vibration levels of assemblies with screws and rivets. Industrially, in many cases the methods of adhesive application offer higher productivity in the assembly processes ${ }^{3}$. Another important advantage resulting from an effective adhesion is a good seal between the bonded parts, inhibiting the passage of fluids through the joint and dispensing with the need for additional impermeabilization ${ }^{4}$.

Several factors can affect the performance of a joint bonded by a structural adhesive, one of these being a variation in temperature ${ }^{5-8}$. These factors have been the focus of several studies reported in the literature, since they allow the identification and prevention of the conditions under which joints may fail and which hinder the good performance of the structure.

In the literature related to this subject there is a concentration of studies involving epoxy adhesives. Taib et al. ${ }^{9}$ studied the strength of joints of polyester composites with glass fiber using epoxy adhesive, while Balkova et al. reported results for the shearing of specimens of pultruded substrates of reinforced polyester with glass 
fiber, bonded with epoxy adhesive, after exposure to a temperature of $60{ }^{\circ} \mathrm{C}^{10}$. The work of Kim et al. ${ }^{7}$, also involving epoxy adhesive, the results showed the effect of the surface treatment of epoxy composites reinforced with carbon fibers under different temperature conditions and the modes of substrate rupture as a function of the surface treatment were evaluated.

The adhesive joint design must be selected considering the nature of its future application. Silva et al. ${ }^{5}$ performed a study to evaluate joints designed with epoxy and bismaleimide adhesives at different temperatures. The joints were manufactured from composites, aluminum and titanium and aimed at aerospace applications. The authors evaluated the distribution of stresses along the joints by way of finite elements analysis.

Malucellia et al. ${ }^{11}$ investigated the shear strength of joints bonded with a monocomponent polyurethane adhesive (base polyester) on substrates of polyoxypropylene, polypropylene and aluminum. The researchers investigated surface treatment methods, kinetics reaction and the thermal behavior of the adhesive and obtained as a result an increase in shear strength after treatment and the speed of the adhesive cure reaction by varying the air humidity and the parameters of the temperature of use. Thus, the aim of the present study was to investigate and evaluate two components urethane structural adhesives using substrates of composite and thermoplastic materials and also to present results of testing conditions which have not been previously extensively evaluated.

\section{Failure Modes Characteristic of Adhesive Joints}

In order to identify the failure modes in shear tests, the guidelines of the ASTM D5573 ${ }^{[12]}$ standard were followed, which classifies the rupture modes of adhesive joints. The main rupture modes suggested by the standard are shown in Figure I.

The factor which determines the failure mode of a specimen is the difference between the cohesive and

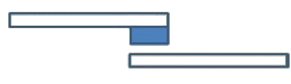

Adhesive failure (ADH)

(a)

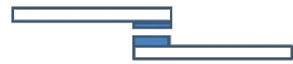

(c)

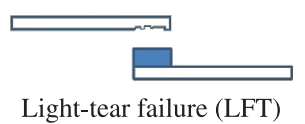

(e)
Thin-layer cohesive failure (TLC)

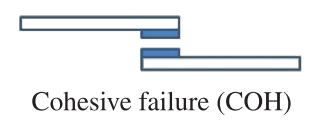

(b)

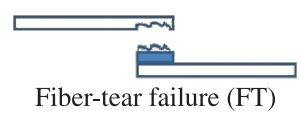

(d)

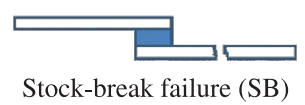

(f)
Figure 1. Representation of failure modes characteristic of adhesive joints submitted to shearing. adhesive resistances and the resistance of the substrate ${ }^{13}$. The failure will firstly occur at the point of least resistance.

The failure of the substrate, in turn, can occur in two ways: stock-break or fiber-tear. The previous concept also applies in these cases, that is, the failure will firstly occur through the path of least resistance Stock-break occurs when the specimen submitted to the shear test breaks outside the bonded area, while in the fiber-tear mode the failure arises when the specimen resists the applied stress but undergoes flexion during the test which can initiate the rupture process.

The failure of anisotropic substrates can occur in both ways. The composites used in this study have this quasi-isotropic character. Defects in the composite substrate such as air bubbles, differences in the polymeric matrix and reinforcement fractions and inefficient impregnation of the fibers favor the fiber-tear process, initiating a rupture process in the region close to the interface with the adhesive. Composite substrates which have a low number of defects tend to undergo stock-break failure.

It should be highlighted that in the analysis of the test results, not only the shear strength values should be considered but also the failure mode, given that in the substrates of composite materials this can occur via both fiber-tear and stock-break modes.

\section{Materials and Methods}

Masterpur Estrutural 300 urethane adhesive manufactured by Urepol-Masterpol Adesivos was used and it was applied with a pneumatic mixing dosing device.

The thermoplastic and composite substrates were produced at an automotive plant. The objective of this study was to investigate the capacity of the urethane structural adhesive to replace the use of mechanical joints with adhesive joints and to demonstrate that the adhesive is as or more efficient than the mechanical joint. ABS is the generic name for a family of amorphous thermoplastics formed by a combination of acrylonitrile monomers, butadiene and styrene which have a high dimensional stability, good surface appearance, easy processability, good electrical insulation and good chemical resistance. It is commonly employed in the manufacturing of parts for buses, for example, fenders, roof, fuel tank protector, and internal door panels, and is molded by the vacuum forming technique.

For the composite specimens laminated polyester reinforced with glass fiber was used, molded using RTM (Resin Transfer Molding) and SMC (Sheet Molding Compound) as used in parts for trucks, cars and buses.

The evaluation of the performance of the adhesive was carried out through the determination of the shear strength using the standard ASTM D3163. Five specimens were tested in each test for each of the proposed conditions and the results represent the average of the measurements and its respective expanded uncertainty. A total of around one hundred specimens were used.

The preparation of the surface of the composite and thermoplastic substrates was carried out by abrasion to remove the surface layer which could interfere in the adherence of the urethane adhesive, followed by cleaning with isopropyl alcohol. 
The tests were conducted 24 hours after the bonding at different temperatures which may occur during the use of the joint in automotive parts. The temperatures applied were based on the norms WSBM11P27B of Ford and TMS 6900 of International Trucks, both restricted use. For the conditioning of the specimens at these temperatures an oven with air circulation and a cold chamber were used.

\section{Results and Discussion}

Firstly, the results for the shear strength at $25{ }^{\circ} \mathrm{C}$ are presented, which serves as a parameter for comparison with the other tests. The results obtained for the specimens at different temperatures are then reported. Lastly, the specimens were exposed to high temperatures followed by stabilization and then the test at ambient temperature.

\subsection{Shear strength of joints bonded at room temperature}

The specimens were tested to evaluate the shear strength at $25^{\circ} \mathrm{C}$ using a Kratos universal testing machine with a load cell of $1000 \mathrm{kgf}$, adopting a test velocity of $12.7 \mathrm{~mm} / \mathrm{min}$. The results together with their respective uncertainties are given in Table 1.

Under the conditions of the test in Table 1 the failures occurred in the substrates while the adhesive remained

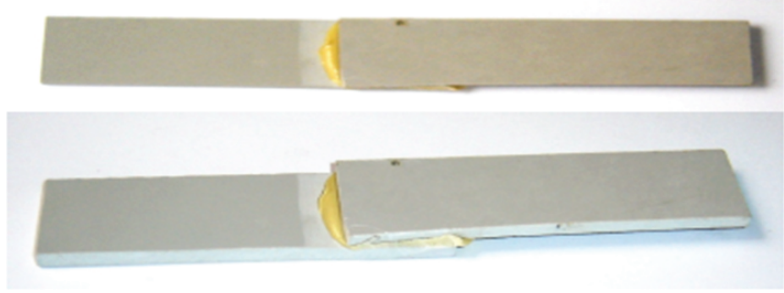

(a) undamaged. In the SMC there was fiber-tear failure and in the RTM and ABS stock-break failure, as shown in Figures 2-4, respectively. For the ABS specimens the shear strength was lower than the values obtained for the SMC and RTM, which can be interpreted as a natural occurrence considering that ABS has a lower tensile strength than the composites. This indicates that the bonding with the adhesive was efficient since the failures occurred in the substrate, maintain the integrity of the adhesive.

The adherence observed for the urethane adhesive is due to the efficient interaction between the adhesive and the substrate. In the case of the composite materials SMC and RTM, which traditionally have a greater percentage of polymeric matrix, it is possible to allow greater interaction between the adhesive and the polymeric matrix of the composite. This interaction can be explained by the high

Table 1. Evaluation of shear strength of joints at $25^{\circ} \mathrm{C}$.

\begin{tabular}{cccc}
\hline Substrate & $\begin{array}{c}\text { Shear } \\
\text { strength } \\
\text { (MPa) }\end{array}$ & $\begin{array}{c}\text { Expanded } \\
\text { uncertainty } \\
\text { (MPa) }\end{array}$ & $\begin{array}{c}\text { Failure } \\
\text { mode }\end{array}$ \\
\hline SMC & 5.8 & 0.4 & Fiber-tear \\
RTM & 6.1 & 0.3 & Stock-break \\
ABS & 3.6 & 0.1 & Stock-break \\
\hline
\end{tabular}

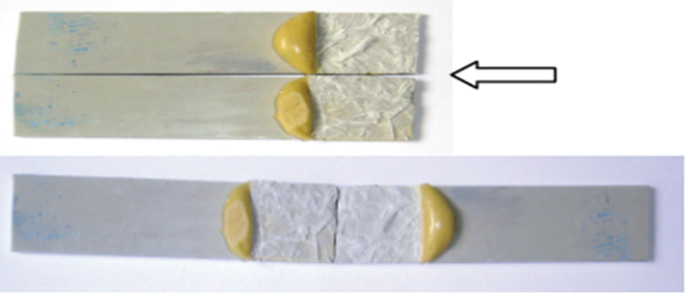

(b)

Figure 2. Test specimens of SMC in adhesive shear test: (a) before the test, (b) after test where the arrow indicates the region of fiber-tear.

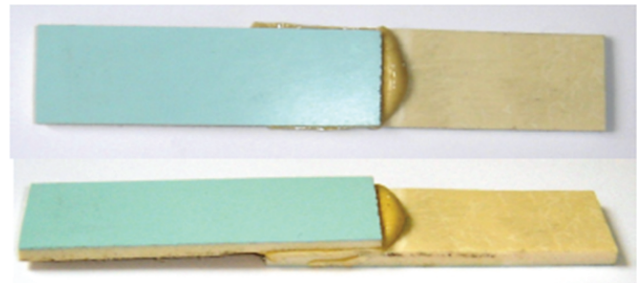

(a)

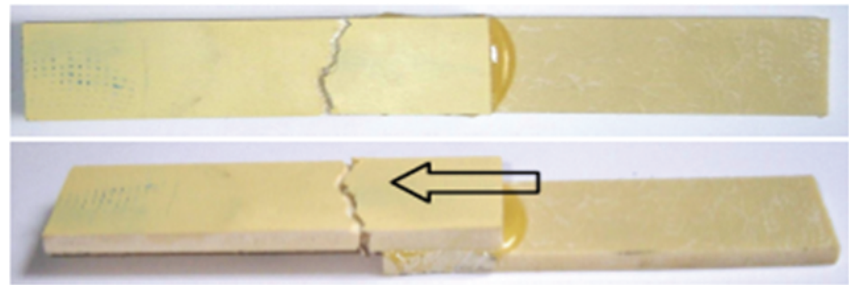

(b)

Figure 3. Test specimens of RTM in adhesive shear test: (a) before the test, (b) after test where the arrows indicate the stock-break.

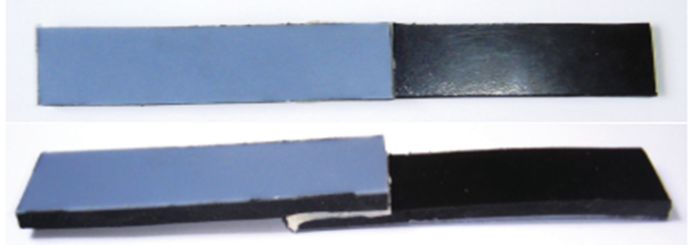

(a)

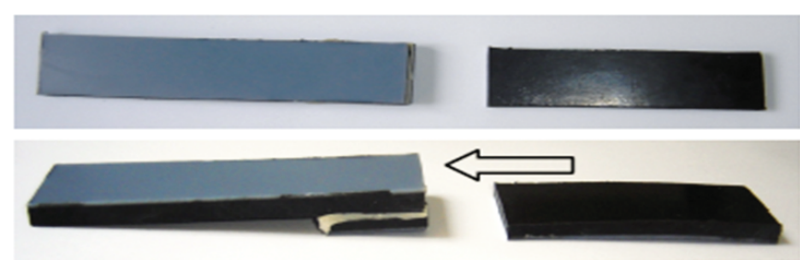

(b)

Figure 4. Test specimens of ABS in adhesive shear test. (a) before the test, (b) after a test where the arrows indicate stock-break. 
polarity of the polyester resin due to the presence mainly of hydroxyl radicals in the polymeric chain ${ }^{14}$, which can interact with the urethane adhesive both electrostatically and through chemical reaction with the isocyanate groups present in the adhesive.

It can be observed in Figure 2 that the rupture of the SMC occurred through fiber-tear and the arrow in the figure indicates the region of the visible fibers. During the test it was observed that the specimens on receiving the mechanical loading underwent flexion leading to the beginning of the failure of the polymeric matrix followed by the rupture of the glass fibers. After the separation of the two parts of the specimen it can be verified that the glass fibers also underwent rupture and became exposed.

In the RTM, according to Figure 3, stock-break failure occurred, in contrast to the fiber-tear mode observed for the SMC.

The SMC substrate underwent flexion and consequently fiber-tear, whereas the RTM substrate showed only slight flexion and this was not sufficient to initiate failure by fiber-tear and instead stock-break failure occurred. The results obtained for the shear strength were $5.8 \pm 0.4 \mathrm{MPa}$ for SMC and 6.1 $\pm 0.3 \mathrm{MPa}$ for RTM.

In the tests carried out with the ABS substrate the failure mode was similar to that observed for the RTM substrate, as shown in Figure 4. It can be observed that the fracture was transversal to the loading direction, presenting a flat form with an aspect characteristic of a pure traction test.

ABS is comprised of three monomers: acrylonitrile (A), butadiene $(\mathrm{B})$ and styrene $(\mathrm{S})^{15}$. Butadiene and styrene are monomers formed of carbon and hydrogen only and the conditions of application are not suitable for their efficient interaction with the urethane adhesive. The acrylonitrile group $\left(\mathrm{H}_{2} \mathrm{C}=\mathrm{CH}-\mathrm{C} \equiv \mathrm{N}\right)$, during the polymerization reacts through the breaking of the $\mathrm{C}=\mathrm{C}$ double bond, the $\mathrm{C} \equiv \mathrm{N}$ group then being available for interaction with the adhesive. This group can form bonds with the hydrogen atoms of the polyol hydroxyl groups of the urethane adhesive.

\subsection{Effect of temperature and time on the shear strength}

For the design of an adhesive joint, besides the properties at ambient temperature it is important to also evaluate the performance under the conditions to which the joint could be submitted after being integrated into a structure. Variations in the temperature and relative air humidity and exposure to corrosive chemical substances, associated with time, are agents which can create conditions which reduce the integrity of the substrate and the adhesive, reducing the load capacity of the joint.

It is recommended that these external conditions are evaluated in isolation and also in a sequence called a cycle, where variations present in the environment where the joint will be used can be simulated. In this study the effects of temperature and time on the behavior of joints bonded with urethane adhesive were investigated.

Since the main use of urethane structural adhesives is in the automotive industry, the external conditions employed in this study were based on the same norms WSBM11P27B and TMS 6900.

\subsubsection{Effect of temperature}

It is known that the use of polymeric materials is restricted when they are submitted to harsh temperature conditions, and maximum temperature limits are almost always established, for instance, 170 or $200{ }^{\circ} \mathrm{C}$. The determination of the conditions at cryogenic temperatures is rare.

In order to determine the shear strength as a function of temperature the tests were carried out under five temperature conditions: $-40,25,80,120$ and $177^{\circ} \mathrm{C}$, after 24 hours of bonding. The test involving temperature is important since it allows the maximum capacity of the joint to bear mechanical loading at different temperatures to be established.

\section{SMC substrate}

The determination of the shear strength as a function of temperature for the SMC substrates was carried out under the five conditions described above and the results can be found in Table 2. The shear strength at $25{ }^{\circ} \mathrm{C}$ represents an initial parameter for comparison with the other values and was established as a reference. The test performed at $-40{ }^{\circ} \mathrm{C}$ led to a reduction in the joint strength of $3.4 \%$ when compared with that at $25{ }^{\circ} \mathrm{C}$, with the occurrence of fiber-tear, however given the uncertainty of the measurement this was not considered to be significant.

In all of the tests conducted at above $25^{\circ} \mathrm{C}$ a decrease in the shear strength occurred for all joints. At $80^{\circ} \mathrm{C}$ there was a reduction in the strength of $10.3 \%$, while at $120^{\circ} \mathrm{C}$ the reduction was $67.2 \%$, with failure occurring via the fiber-tear mode at both temperatures. This indicates that the laminated matrix of the SMC was probably affected by temperatures above $80^{\circ} \mathrm{C}$. At a temperature of $177{ }^{\circ} \mathrm{C}$ there was cohesive failure, with the joint showing a strength of $0.5 \mathrm{MPa}$, which represents a reduction of $91.4 \%$. Under this condition the failure occurred soon after the beginning of the test which is why the strength was so low. If this temperature had not affected the adhesive, the rupture of the substrate would probably have occurred at a value lower that those observed at $120^{\circ} \mathrm{C}$.

\section{RTM substrate}

In a way analogous to that of SMC, a study was carried out using RTM substrates. The RTM fibers are arranged in the form of sheets, while the SMC material is comprised of a mixture of fibers cut with resin and mineral loads. The results obtained for the RTM joints at temperatures of -40 , 25, 80, 120 and $177^{\circ} \mathrm{C}$ can be observed in Table 3 .

The test carried out at $-40^{\circ} \mathrm{C}$ showed a reduction of only $3.3 \%$ in the shear strength compared with that conducted at ambient temperature, and led to stock-break failure.

Table 2. Shear strength of SMC specimens at different temperatures.

\begin{tabular}{ccccc}
\hline $\begin{array}{c}\text { Temperature } \\
\left({ }^{\circ} \mathbf{C}\right)\end{array}$ & $\begin{array}{c}\text { Shear } \\
\text { strength } \\
(\mathbf{M P a})\end{array}$ & $\begin{array}{c}\text { Expanded } \\
\text { uncertainty } \\
(\mathbf{M P a})\end{array}$ & $\begin{array}{c}\text { Variation } \\
(\boldsymbol{\%})\end{array}$ & $\begin{array}{c}\text { Failure } \\
\text { mode }\end{array}$ \\
\hline-40 & 5.6 & 0.4 & -3.4 & Fiber-tear \\
25 & 5.8 & 0.4 & --- & Fiber-tear \\
80 & 5.2 & 0.3 & -10.3 & Fiber-tear \\
120 & 1.9 & 0.1 & -67.2 & Fiber-tear \\
177 & 0.5 & 0.1 & -91.4 & Cohesive \\
\hline
\end{tabular}


Once again, at all temperatures above $25^{\circ} \mathrm{C}$ a decrease in the shear strength occurred. At $80{ }^{\circ} \mathrm{C}$ there was an $18 \%$ reduction while at $120^{\circ} \mathrm{C}$ the reduction was greater, with a value of $65.6 \%$. At both temperatures stock-break failure occurred, which indicates that the specimens were affected by the temperature, this being attributed to the polymeric matrix. The test performed at $177{ }^{\circ} \mathrm{C}$ led to cohesive failure, with a strength of only $0.4 \mathrm{MPa}$, which represents a significant reduction in relation to the ambient temperature. Since the failure was cohesive, the urethane adhesive was demonstrated to not be suitable for application at such high temperatures, as in the case of SMC.

\section{ABS substrate}

The study on the ABS specimens was carried out under the same conditions applied to the SMC and RTM composites, except for the exposure to temperatures above

Table 3. Shear strength of RTM specimens at different temperatures.

\begin{tabular}{ccccc}
\hline $\begin{array}{c}\text { Temperature } \\
\left({ }^{\circ} \mathbf{C}\right)\end{array}$ & $\begin{array}{c}\text { Shear } \\
\text { strength } \\
(\mathbf{M P a})\end{array}$ & $\begin{array}{c}\text { Expanded } \\
\text { uncertainty } \\
(\mathbf{M P a})\end{array}$ & $\begin{array}{c}\text { Variation } \\
(\%)\end{array}$ & $\begin{array}{c}\text { Failure } \\
\text { mode }\end{array}$ \\
\hline-40 & 5.9 & 0.3 & -3.3 & Stock-break \\
25 & 6.1 & 0.3 & --- & Stock-break \\
80 & 5.0 & 0.2 & -18.0 & Stock-break \\
120 & 2.1 & 0.1 & -65.6 & Stock-break \\
177 & 0.4 & 0.1 & -93.4 & Cohesive \\
\hline
\end{tabular}

Table 4. Shear strength of ABS specimens at different temperatures.

\begin{tabular}{ccccc}
\hline $\begin{array}{c}\text { Temperature } \\
\left({ }^{\circ} \mathbf{C}\right)\end{array}$ & $\begin{array}{c}\text { Shear } \\
\text { strength } \\
(\mathbf{M P a})\end{array}$ & $\begin{array}{c}\text { Expanded } \\
\text { uncertainty } \\
(\mathbf{M P a})\end{array}$ & $\begin{array}{c}\text { Variation } \\
(\%)\end{array}$ & $\begin{array}{c}\text { Failure } \\
\text { mode }\end{array}$ \\
\hline-40 & 3.4 & 0.1 & -5.6 & Stock-break \\
25 & 3.6 & 0.1 & --- & Stock-break \\
80 & 3.6 & 0.1 & 0 & Stock-break \\
\hline
\end{tabular}

Table 5. Shear strength of SMC, RTM and ABS specimens subjected to condition 1 - exposure for 500 hours at $90{ }^{\circ} \mathrm{C}$.

\begin{tabular}{ccccc}
\hline Substrate & $\begin{array}{c}\text { Shear } \\
\text { strength } \\
\text { condition 1 } \\
\text { (MPa) }\end{array}$ & $\begin{array}{c}\text { Expanded } \\
\text { uncertainty } \\
(\mathbf{M P a})\end{array}$ & $\begin{array}{c}\text { Variation } \\
\mathbf{( \% )}\end{array}$ & $\begin{array}{c}\text { Failure } \\
\text { mode }\end{array}$ \\
\hline SMC & 5.5 & 0.4 & -5.2 & Stock-break \\
RTM & 5.9 & 0.3 & -3.3 & Stock-break \\
ABS & 3.4 & 0.1 & -5.6 & Stock-break \\
\hline
\end{tabular}

Table 6. Shear strength of SMC and RTM specimens subjected to condition 2-20 minutes exposure to $177^{\circ} \mathrm{C}$.

\begin{tabular}{ccccc}
\hline Substrate & $\begin{array}{c}\text { Shear } \\
\text { strength } \\
\text { condition 2 } \\
\text { (MPa) }\end{array}$ & $\begin{array}{c}\text { Expanded } \\
\text { uncertainty } \\
\text { (MPa) }\end{array}$ & $\begin{array}{c}\text { Variation } \\
(\mathbf{\%})\end{array}$ & $\begin{array}{c}\text { Failure } \\
\text { mode }\end{array}$ \\
\hline SMC & 3.4 & & -41.4 & Fiber-tear \\
RTM & 3.2 & & -47.5 & Fiber-tear \\
\hline
\end{tabular}

$120^{\circ} \mathrm{C}$, since the substrate would not resist such conditions. The results obtained for the ABS joints at temperatures of $-40,25$ and $80^{\circ} \mathrm{C}$ are shown in Table 4 .

The test carried out at $-40{ }^{\circ} \mathrm{C}$ showed a reduction of $5.6 \%$, which is higher than in the case of SMC and RTM, with stock-break failure occurring. At $80{ }^{\circ} \mathrm{C}$ there was no variation in the shear strength and the ABS showed the same failure mode as that observed at ambient temperature, indicating that at $80{ }^{\circ} \mathrm{C}$ the $\mathrm{ABS}$ did not undergo degradation.

\subsubsection{Effect of temperature and time of joint exposure}

The shear strength of the bonded joints was evaluated after exposure to high temperatures for a period of time followed by stabilization at $25^{\circ} \mathrm{C}$ and testing. Two conditions were evaluated according to the requirements of the norms WSBM11P27B and TMS 6900 for vehicles. The first was exposure to $90{ }^{\circ} \mathrm{C}$ for 500 hours (condition 1) and the second exposure to $177^{\circ} \mathrm{C}$ for 20 minutes (condition 2). In the case of condition 1 the objective was to evaluate the effect of temperature for a long exposure time while in the case of condition 2 the aim was to evaluate the effect of a high temperature peak for a short period of time. For both conditions, according to the guidelines of the cited norms, at the end of the exposure to the respective temperatures for the set times the test was carried out at ambient temperature. Tables 5 and 6 show the shear strength results at a temperature of $25{ }^{\circ} \mathrm{C}$ after the exposures described above.

On comparing these results with those obtained under the initial condition of $25^{\circ} \mathrm{C}$ (section 4.1), it can be noted that there was a slight reduction in the shear strength for condition 1 and the decrease was more accentuated for condition 2 . These findings were attributed to the fragilization of the substrates.

In the case of the SMC which had a strength of $5.8 \pm 0.4 \mathrm{MPa}$ at $25{ }^{\circ} \mathrm{C}$ with a fiber-tear failure, condition 1 led to a $5.2 \%$ reduction and the failure mode was different, this time occurring via the stock-break mode. Applying condition 2 led to fiber-tear failure with a reduction in the shear strength of $41.4 \%$. For the RTM, condition 1 led to a $3.3 \%$ reduction while condition 2 resulted in a $47.5 \%$ reduction in shear strength and the failure modes were, respectively, stock-break and fiber-tear. It can be observed that the effects of conditions 1 and 2 were very similar for the RTM and SMC both in terms of the reduction in strength and the percentage reduction.

It was observed for the composite substrates that the greater the exposure temperature, even for a shorter time, the greater the effect of the strength reduction of the joint. The effect of a temperature of $177^{\circ} \mathrm{C}$ with a short exposure time, only 20 minutes, was considerably more destructive than the long exposure (500 hours) to a lower temperature of $90^{\circ} \mathrm{C}$.

In the case of the ABS substrates it was not possible to evaluate the behavior at $177^{\circ} \mathrm{C}$ due to its low melting temperature $\left(105^{\circ} \mathrm{C}\right)$. Thus, only condition 1 was applied and there was a reduction of $5.6 \%$ with failure occurring via the stock-break mode, a result close to that observed for the SMC substrate. 


\section{Conclusions}

The urethane adhesive showed an excellent performance in the bonding of composite and thermoplastic joints within the temperature range of -40 to $120^{\circ} \mathrm{C}$, showing a rupture of the substrate outside the bonding area. This shows that the adhesive was able to bear the mechanical force without undergoing failure. For a condition of $177^{\circ} \mathrm{C}$ there was a considerable reduction in the shear strength with cohesive failure, indicating that the adhesive cannot be recommended for continuous use at this temperature.

The results showed that application of the conditions of 500 hours $/ 90{ }^{\circ} \mathrm{C}$ and 20 minutes $/ 177^{\circ} \mathrm{C}$ led to a decrease

\section{References}

1. Baldan A. Adhesively-bonded joints in metallic alloys, polymers and composite materials: Mechanical and environmental durability performance. Journal of Materials Science. 2004; 39:4729-4797. http://dx.doi.org/10.1023/ B:JMSC.0000035317.87118.ab

2. Hou TH, Boston KG, Baughman JM, Walker S and Johnston WM. Composite-to-composite Bonding using Scotch-Weld ${ }^{\mathrm{TM}}$ AF-555M Structural Adhesive. Journal of Reinforced Plastics and Composites. 2010; 29(11):1702-1711. http://dx.doi. org/10.1177/0731684409341679

3. Stewart R, Goodship V, Guild F, Green M and Farrow F. Investigation and demonstration of the durability of air plasma pre-treatment on polypropylene automotive bumpers. International Journal of Adhesion and Adhesives. 2005; 25:9399. http://dx.doi.org/10.1016/j.ijadhadh.2004.04.001

4. Borsellino C, Calabrese L, Bella G and Valenza A. Comparisons of processing and strength properties of two adhesive systems for composite joints. International Journal of Adhesion and Adhesives. 2007; 27:446-457. http://dx.doi.org/10.1016/j. ijadhadh.2006.01.012

5. Silva LFM and Adams RD. Joint strength predictions for adhesive joints to be used over a wide temperature range. International Journal of Adhesion and Adhesives. 2007; 27:362-379. http://dx.doi.org/10.1016/j.ijadhadh.2006.09.007

6. Goeiju WC, Tooren VMJL and Beukers A. Composite adhesive joints under cyclic loading. Materials \& Design. 1999; 20:213221. http://dx.doi.org/10.1016/S0261-3069(99)00032-1

7. Kim JK and Lee DG. Characteristics of plasma surface treated composite adhesive joints at high environmental in the shear strength due to failures in the substrates. This results from the effect of the exposure temperatures being above the $\mathrm{Tg}$ of the polymeric matrix of the composite substrates and also above the ABS deformation temperature, which leads to a breaking of the polymeric chains fragilizing the substrate. No alterations in the behavior of the adhesive was observed at these temperatures

\section{Acknowledgements}

The authors acknowledge the technical support of the Masterpol Adhesives Technology and IPEN-Energetic and Nuclear Research Institute.

temperature. Composite Structure. 2002; 57:37-46. http:// dx.doi.org/10.1016/S0263-8223(02)00060-0

8. Khalili SMR, Mittal RK and Kalibar SG. A study of the mechanical properties of steel/aluminium/GRP laminates. Materials Science and Engineering: A. 2005; 412:137-140. http://dx.doi.org/10.1016/j.msea.2005.08.016

9. Taib AA, Boukhili R, Achiou S, Gordon S and Boukehili H. Bonding composites. International Journal of Adhesion and Adhesives. 2006; 26:226-236.

10. Balkova R, Holcnerova S and Cech V. Testing of adhesives for bonding of polymer composites. International Journal of Adhesion and Adhesives. 2002; 22:291-295. http://dx.doi. org/10.1016/S0143-7496(02)00006-4

11. Malucelli G, Priolla A, Ferrero F, Quaglia A, Frigione M and Carfagna C. Polyurethane resin-based adhesives: curing reaction and properties of cured systems. International Journal of Adhesion and Adhesives. 2005; 25:87-91.

12. American Society for Testing and Materials - ASTM. ASTM D5573: Standard Practice for Classifying Failure Modes in Fiber-Reinforced-Plastic (FRP) Joints. ASTM; 2005.

13. Cognard P. Handbook of adhesives and sealants. Versailles: Elsevier; 2006. v. 2.

14. Sanchez EMS. Influence of addition of poly (styrene- $b$ isoprene-b-styrene) resins on the mechanical properties. [Tese]. Campinas: Universidade Estadual de Campinas; 1996.

15. Brady GS, Clauser HR and Vaccari JA. Materials Handbook. 15th ed. New York: McGraw-Hill; 2002. 